\title{
Principles of Airway Management, 4th Edition
}

\author{
Brendan T. Finucane, Ban C.H. Tsui, Albert Santora. Springer, 2010. \\ ISBN: 978-0-387-09557-8
}

\author{
Arnaud Robitaille
}

Received: 11 June 2012/ Accepted: 3 July 2012/Published online: 18 July 2012

(c) Canadian Anesthesiologists' Society 2012

The fourth edition of Principles of Airway Management is a comprehensive work covering virtually all aspects of the adult and pediatric airway that any professional can hope to learn from a textbook. Indeed, its 15 chapters encompass the following topics: anatomy of the airway, evaluation of the airway, basic emergency airway management and cardiopulmonary resuscitation, basic equipment for airway management, the $\mathrm{LMA}^{\mathrm{TM}}$ and other supraglottic devices, advanced airway devices (including fibreoptic laryngoscopes, videolaryngoscopes, stylets, and light wands), indications and preparation of the patient for tracheal intubation, techniques of intubation, the difficult airway, pediatric airway management, fibreoptically guided airway management techniques, surgical options in airway management, mechanical ventilation and respiratory care, extubation strategies, and, finally, complications of airway management.

This book is well written throughout, and the comprehensive table of contents and index enable the reader to easily find information in this lengthy textbook. The tables and figures have been improved in this edition and most are of good quality. The references are up-to-date.

While the preponderance of expertise in airway management can be acquired only through experience, both novices and experts alike will gain insight into airway management by consulting this book. It provides the basic information useful to the beginner and the more advanced content useful to the expert. The book strikes the right balance between theoretical and technical information, which is another important quality. The authors offer the greatest extent of practical "how to" information in a textbook, notably because of the numerous figures.

Although this 742-page textbook is indeed quite complete, some advanced techniques, e.g., rigid bronchoscopy, jet ventilation, and lung isolation, are covered hastily and without much technical detail. This is unfortunate since an expert might consult this textbook specifically for information regarding these perhaps less commonly used techniques. In contrast, some topics, e.g., cardiopulmonary resuscitation, are reviewed in surprising detail for a textbook dealing with airway management.

Overall, this fourth edition of Principles of Airway Management constitutes a very good reference for any individual or organization interested in airway management. The depth of information goes well beyond that available in more "general" anesthesia textbooks, such as Miller's Anesthesia, Seventh Edition by Ronald D. Miller and Clinical Anesthesia, Sixth Edition by Paul Barash.

Competing interests None declared.

A. Robitaille ( $\square)$

Université de Montréal, Montreal, QC, Canada

e-mail: arnaud.robitaille@umontreal.ca 